\title{
PEMBELAJARAN SEJARAH ASIA BARAT KUNO BERBASIS PARADIGMA PEDAGOGI REFLEKTIF
}

\section{LEARNING HISTORY OF ANCIENT WEST ASIA BASED ON REFLECTIVE PEDAGOGIC PARADIGM}

\author{
Brigida Intan Printina $^{1}$, Anju Nofarof Hasudungan ${ }^{2}$ \\ ${ }^{1}$ Pendidikan Sejarah Universitas Sanata Dharma \\ ${ }^{2}$ Sekolah Menengah Atas Negeri 1 Rupat \\ e-mail: intanbrigida@usd.ac.id
}

\begin{abstract}
Abstrak: Penelitian bertujuan untuk menganalisis perencanaan, pelaksanaan dan evaluasi dalam penerapan Paradigma Pedagogi Reflektif serta memanfaatkan media komik dalam perkuliahan Sejarah Asia Barat Kuno. Metode penelitian menggunakan penelitian kualitatif deskriptif. Data penelitian dikumpukan melalui pengamatan, analisis dokumen dan wawancara dengan mahasiswa di kelas Sejarah Asia Barat Kuno Program Studi Pendidikan Sejarah FKIP Universitas Sanata Dharma Yogyakarta. Pengujian data dilakukan melalui triangulasi data, triangulasi metode, triangulasi peneliti, dan triangulasi teoritis. Penelitian ini menggunakan metode analisis interaktif. Hasil penelitian menunjukkan dengan perencanaan, pelaksanaan dan evaluasi yang benar dalam penerapan Paradigma Pedagogi Reflektif serta media komik yang menarik pada mata kuliah Sejarah Asia Barat Kuno. Maka, mahasiswa mengalami peningkatan pada aspek 3C yaitu, competence, conscience, compassion. Bagi para civitas akademika, hasil penelitian ini diharapkan dapat mengintegrasikan pengajaran dengan penelitian secara maksimal sehingga manfaatnya dapat dirasakan bersama dan mampu dimaknai sebagai salah satu modal pembangunan bangsa.
\end{abstract}

Kata kunci: Pembelajaran Sejarah, Paradigma Pedagogi Reflektif, Komik, Perguruan Tinggi

Abstract: The research aims to analyze planning, implementation and evaluation in the application of the Reflective Pedagogical Paradigm as well as utilizing comic media in Ancient West Asian History lectures. This study uses descriptive qualitative research. The research data was collected through observations, document analysis and interviews with students in the Class of Ancient West Asian History. Data testing was done through data triangulation, method triangulation, researcher triangulation, and theoretical triangulation. This study uses an interactive analysis method. The results showed that the correct planning, implementation and evaluation in the application of the Reflective Pedagogical Paradigm and comic media were interesting in the course of Ancient West Asian History. So, students experience an increase in the 3C aspects, namely, competence, conscience, compassion. For the academic community, the results of this study are expected to be able to optimally integrate teaching with research so that the benefits can be shared and can be interpreted as one of the assets of nation development.

Keywords: Historical Learning, Reflective Pedagogy Paradigm, Comic, Higher Educatio 


\section{PENDAHULUAN}

Pelaksanaan pembelajaran Sejarah Asia Barat Kuno merupakan satu diantara mata kuliah wajib yang ditawarkan pada semester II, sesuai dengan kurikulum 2016 Prodi Pendidikan Sejarah Universitas Sanata Dharma. Mahasiswa pada semester genap tahun ajaran 2019/2020 diperkenalkan dengan beberapa mata kuliah sejarah kawasan diantaranya Sejarah Asia Barat Kuno. Relevansi yang erat kaitannya dengan mata kuliah ini ialah sejarah masuk dan berkembangnya islamisasi di Indonesia. Mengingat bahwa Indonesia menjadi negara dengan jumlah penduduk Muslim terbesar di dunia. Dengan mempelajari sejarah kawasan ini (Sejarah Asia Barat Kuno) yang erat kaitannya dengan sejarah Indonesia tersebut mahasiswa mendapat pengetahuan lebih ketika harus menguraikannya di hadapan peserta didiknya kelak.

Perkuliahan sejarah kawasan khususnya Sejarah Asia Barat Kuno akan terasa kering makna jika tidak dikemas dengan strategi pembelajaran yang inspiratif. Salah satu pemecahan masalahnya ialah peneliti sekaligus dosen pengampu menerapkan pendekatan atau Paradigma Pedagogi Reflektif (PPR) sebagai sarana pengajaran yang interaktif dan inspiratif.

Sebagai calon pendidik sejarah mahasiswa tidak hanya mengenal teori sebagai bahan ajarnya namun juga harus memaknai dan menemukan relevansi konteks dengan makna kehidupan, sehingga pembelajaran sejarah ditingkat menengah tidak kehilangan arah dan mampu menghidupi nilai-nilai moral dan budaya yang telah dibangun dengan penuh perjuangan oleh para pendiri bangsa.

Dengan perkuliahan yang penuh konteks mahasiswa dituntut untuk mampu memaknai kehidupan masyarakat arab pra-Islam, perubahan masyarakat pada masa Muhammad SAW, perkembangan dinasti sesudahnya dan dampak kebudayaan Arab bagi dunia serta Indonesia. Lebih dari itu penelitian ini, ingin menggambarkan tentang Paradigma Pedagogi Reflektif (PPR) sebagai sarana yang efektif untuk pembelajaran Sejarah Asia Barat Kuno.

Suparno menjelaskan bahwa Paradigma Pedagogi Reflektif adalah pendekatan yang menekankan perkembangan pengertahuan, hati, dan karakter siswa (Melissa, 2017). Lebih lanjut (Melissa, 2017) menambahkan bahwa Paradigma Pedagogi Reflektif (PPR) adalah pedagogi, yaitu cara pendidik mendampingi peserta didik berkembang menjadi pribadi yang utuh bukan sekedar metode pembelajaran. Dari berbagai latar belakang di atas maka peneliti memilih menganalisis perencanaan, pelaksanaan dan evaluasi Pembelajaran Sejarah Asia Barat Kuno berbasis Paradigma Pedagogi Reflektif (PPR). 


\section{METODE}

Jenis peneltitian yang digunakan ialah penelitian kualitatif deskriptif. Pada penerapannya penelitian ini lebih menekankan pada kegiatan maupun informasi tentang keadaan yang sedang berlangsung yang bertujuan memperoleh proses dan makna. Sutopo (2006) menyatakan sifat penelitian deskriptif kualirarif berarti penelitian kualitatif yang selalu menyajikan temuannya dalam bentuk deskripsi kalimat yang rinci, lengkap, dan mendalam mengenai proses mengapa dan bagaimana sesuatu terjadi. Dengan menggunakan penelitian kualitatif deskriptif, peneliti akan mampu menangkap berbagai informasi kualitatif deskripsi dengan teliti (Sutopo, 2006).

Adapun sumber data dalam penelitian ini diantaranya: 1) Informan atau narasumber merupakan beberapa mahasiswa yang diambil dari perkuliahan Sejarah Asia Barat Modern; 2) Tempat pelaksanaan penelitian ialah di ruang II/K 34; 3) Dokumen yang dikaji merupakan perangkat pembelajaran diantaranya RPS, RTP, RP, Media komik yang dibuat oleh mahasiswa pada mata kuliah Sejarah Asia Barat Modern.

Teknik Pengumpulan data penelitian meliputi; 1) Observasi yang digunakan untuk menggali data dari sumber data yang berupa peristiwa, aktivitas, perilkau, tempat atau lokasi, dan benda serta rekaman gambar. penelitian ini, observarsi berperan pasif dilakukan ketika berlangsungnya proses pembelajaran yang memanfaatkan komik sebagai media pembelajaran, dalam hal ini ialah media komik; 2) pencatatan dokumen menurut Yin (Sutopo, 2006) disebut sebagai kontent analisis, sebagai cara untuk menemukan beragam hal sesuai dengan kebutuhan dan tujuan penelitian. Peneliti tidak sekedar mencatat isi penting yang tersurat dalam dokumen tetapi juga tentang maknanya yang tersirat. Dalam penelitian ini, dokumen yang dikumpulkan meliputi perangkat pembelajaran sejarah Asia Barat Modern. Penelitian ini menggunakan teknik cuplikan yang dikenal dengan purposive sampling (sample bertujuan). Teknik purposive sampling dalam penelitian ini bersifat criterion-based selection (Sutopo, 2006). Pengujian data dilakukan melalui triangulasi data, triangulasi metode, triangulasi peneliti, dan triangulasi teoritis Pengujian data dilakukan melalui triangulasi data, triangulasi metode, triangulasi peneliti, dan triangulasi teoritis 


\section{HASIL DAN PEMBAHASAN}

\section{Persiapan pembelajaran Sejarah Asia Barat Kuno berbasis PPR}

Hasil penelitian disusun berdasarkan hasil pengamatan pada pembelajaran Sejarah Asia Barat Kuno semester genap tahun ajaran 2019/2020. Objek penelitian ini adalah mahasiswa program studi Pendidikan Sejarah Fakultas Keguruan dan Ilmu Pendidikan Universitas Sanata Dharma Yogyakarta. Penelitian dilakukan di ruang K.19 setiap Selasa pukul 14.0016.00. Pada pertengahan Maret, pembelajaran dilakukan secara jarak jauh maka peneliti menggambarkan hasil penugasan dan evaluasi akhir mahasiswa angkatan 2019 prodi pendidikan sejarah. Peneliti menggunakan web belajar untuk melakukan Pembelajaran Jarak Jauh (PJJ). Para mahasiswa diberikan beberapa penugasan secara berkelompok sebelum masa pandemi Covid-19.

Perkuliahan tatap muka hanya sampai berlangsung pada pertemuan ke 5. Seanjutnya mahasiswa melakukan presentasi secara live streaming melalui Youtube. Dosen juga menggunakan web belajar sebagai saran kuliah Daring.

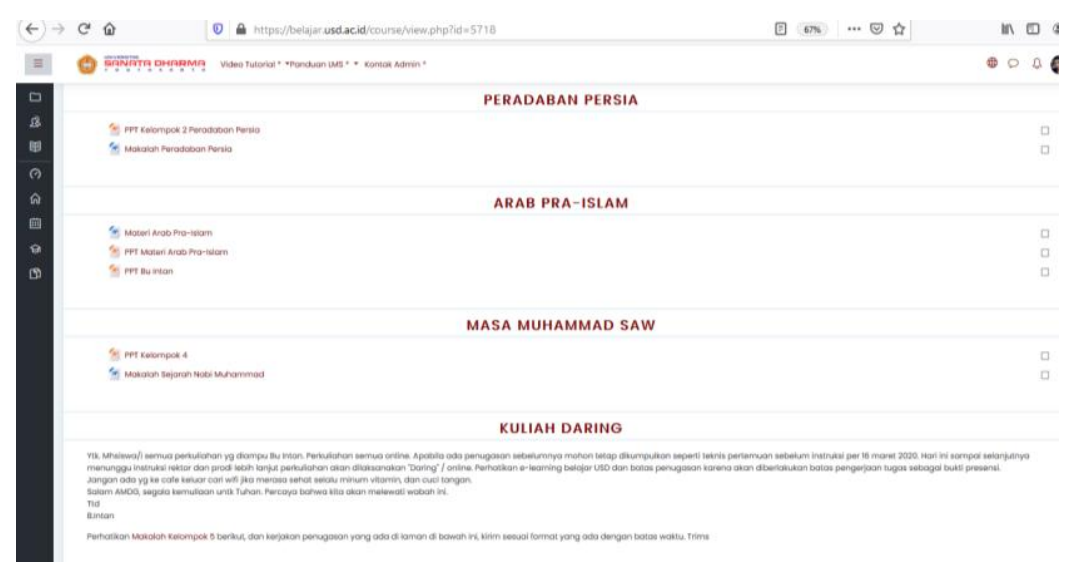

Gambar 1.1. Web Belajar sebagai sarana PJJ

Perkuliahan sejarah kawasan khususnya Sejarah Asia Barat Kuno akan terasa kering makna jika tidak dikemas dengan strategi pembelajaran yang inspiratif. Salah satu pemecahan masalahnya ialah peneliti sekaligus dosen pengampu menerapkan pendekatan atau Paradigma Pedagogi Reflektif (PPR) sebagai sarana pengajaran yang interaktif dan inspiratif. Hasil penelitian dari (Wijoyo et al., 2016) menunjukkan adanya peningkatan kemampuan dosen dalam mengelola strategi pembelajaran berbasis PPR juga Penerapan strategi pembelajaran berbasis PPR mampu meningkatkan kompetensi dan keterampilan serta kemampuan refleksi mahasiswa. 
Guna ilmu sejarah satu diantaranya adalah inspiratif. Maksudnya adalah Mendapat inspirasi dari sejarah yang diceritakan (Sulaiman, 2012). PPR menjadi pendekatan pedagogi bagaimana dosen dapat membantu mahasiswa untuk berkembang menjadi pribadi yang utuh dan mampu mendapatkan nilai inspiratif dalam proses pembelajaran Sejarah Asia Barat Kuno. Dengan perkuliahan yang penuh konteks mahasiswa dituntut untuk mampu memaknai kehidupan masyarakat arab pra-Islam, perubahan masyarakat pada masa Muhammad SAW, perkembangan dinasti sesudahnya dan dampak kebudayaan Arab bagi dunia serta Indonesia.

Sebagai calon pendidik sejarah mahasiswa tidak hanya mengenal teori sebagai bahan ajarnya namun juga harus memaknai dan menemukan relevansi konteks dengan makna kehidupan, sehingga pembelajaran sejarah di tingkat menengah tidak kehilangan arah dan mampu menghidupi nilai-nilai moral dan budaya yang telah dibangun dengan penuh perjuangan oleh para pendiri bangsa. Pemilihan PPR sebagai pedagogi pembelajaran harus dipersiapkan dengan sebaik mungkin karena persiapan yang baik dan tepat menjadi faktor penting untuk tercapainya tujuan pembelajaran Sejarah Asia Barat Kuno.

Qasim \& Maskiah (2016) menyatakan bahwa terdapat dua poin yang penting diperhatikan dalam perencanaan pengajaran oleh setiap tenaga pendidik. Pertama, persiapan dalam merencanakan kegiatan pembelajaran. Kegiatan ini meliputi, mengenal kondisi mahasiswa, memahami karakteristik mahasiswa, memahami gaya belajar dan kemampuan mahasiswa; serta memiliki kompetensi sebagai tenaga pendidik profesional. Kedua, kegiatan dalam perencanaan pengajaran, meliputi, mengembangkan silabus, dan menyusun Rencana Pembelajaran Semester (RPS)

Oleh karena itu, dalam persiapan pembelajaran Sejarah Asia Barat Kuno berbasis Paradigma Pedagogi Reflektif agar dapat mencapai tujuan yang hendak dicapai maka perlu dilakukan beberapak kegiatan. Yakni, mengenal kondisi yang mengitari mahasiswa, memahami karakteristik mahasiswa, memahami gaya belajar dan kemampuan mahasiswa; serta memiliki kompetensi sebagai tenaga pengajar professional. Dan kegiatan dalam perencanaan pengajaran, meliputi, mengembangkan silabus, dan menyusun Rencana Pembelajaran Semester (RPS).

Mangenal dan memahami mahasiwa yang akan diajar pada mata kuliah Sejarah Asia Barat Kuno menjadi bagian penting dari PPR. Perihal kegiatan dalam perencanaan pengajaran, meliputi, mengembangkan silabus, dan menyusun Rencana Pembelajaran Semester (RPS) diupayakan dengan mengintegrasikan tiga hal utama dalam pelaksanaan Jurnal Swadesi, Volume I Nomor 1 Tahun 2020 
pembelajaran dengan menggunakan Paradigma Pedagogi Reflektif (PPR), yaitu pengalaman, refleksi, dan aksi. Dalam melaksanakan ketiga unsut itu, fasilitator dibantu oleh unsur konteks sebelum pembelajaran dimulai dan evaluasi pembelajaran dilaksanakan. Perencanaan pengajaran merupakan satu tahapan dalam proses pembelajaran. berusaha sedapat mungkin agar pengajarannya berhasil. Salah satu faktor yang bisa membawa keberhasilan itu ialah bahwa sebelum masuk ke dalam kelas, tenaga pendidik senantiasa membuat perencanaan pengajaran sebelumnya (Qasim \& Maskiah, 2016).

Pratini (2016) menyarankan agar proses pembelajaran berbasis PPR dirancang sedemikian rupa sehingga mahasiswa yang menjadi pusat proses belajar mampu menemukan diri dalam kesadarannya untuk menggali pengetahuan serta membangun hati nurani yang benar dan kepedulian dengan penuh tanggungjawab.

Ada lima langkah pembelajaran PPR yang mengakar pada 3 capaian pembelajaran secara umum. Pertama competence, yang mengarah pada penggalian konteks setiap individu dalam memahami konsep dan mampu menganalisanya sebagai suatu modal untuk melihat gejala kehidupan yang lebih luas. Dalam hal ini, mahasiswa dapat memahami bentuk peristiwa yang terjadi pada pembelajaran Sejarah Asia Barat Kuno, misalnya pembaharuan pasca Arab pra-Islam, dan perkembangan Dinasti dengan berbagai pola yang ada.

Kedua compassion, pada bagian ini para mahasiswa diajak untuk menggali pengalaman bahwa dengan segala bentuk peristiwa yang terjadi dapat menganalisis peristiwa tersebut dan membaginya dalam sebuah kisah berbeda dan pola yang sama dibeberapa belahan dunia, hal ini sebagai modal dasar dalam menyampaikan islamisasi yang masuk ke Indonesia dalam Sejarah Indonesia tingkat Sekolah Menengah.

Ketiga conscience \& commitment, mahasiswa diajak untuk dapat menggali suara hati dan melakukan tindakan atas refleksi yang sudah dilakukan yaitu berupa aksi. Mahasiswa pada perkuliahan Sejarah Asia Barat Kuno diajak untuk menciptakan modul pembelajaran sesuai dengan topik yang diberikan dalam penugasan kelompok agar tercipta produk yang dapat dirasakan tidak hanya diperkuliahan ini namun digunakan sebagai bahan ajar di tingkat sekolah menengah. Bahan ini akan berguna ketika mereka mengajar kelak menjadi pendidik sejarah.

PPR adalah pendekatan pembelajaran dengan menerapkan refleksi dalam setiap proses untuk mendapatkan makna berdasarkan hierarki nilai, norma dan hati nurani. Hal tersebut menentukan perilaku yang bertanggung jawab dengan menjunjung tinggi kemanusiaan. Jurnal Swadesi, Volume I Nomor 1 Tahun 2020 
Pendekatan pembelajaran dengan memberikan pengalaman yang dimiliki mahasiswa tidak hanya menyampaikan pembelajaran dengan kerangka pengetahuan. Dalam siklus pembelajaran penerapan PPR terdapat lima tahapan yaitu konteks, pengalaman, refleksi, tindakan dan evaluasi

\section{Pelaksanaan Pembelajaran Sejarah Asia Barat Kuno berbasis PPR}

Setelah persiapan pembelajaran Sejarah Asia Barat Kuno berbasis Paradigma Pedagogi Reflektif telah diselesaikan. Maka selanjutnya diterapkan dalam pembelajaran Sejarah Asia Barat Kuno pada mahasiswa program studi pendidikan sejarah Universitas Sanata Dharma (USD). Menurut Wijoyo, dkk menyatakan bahwa Reflective Pedagogy Paradigm (RPP) dapat meningkatkan performa dosen dalam mengajar, meningkatkan kesiapan dosen dalam mengajar, dan menjadikan mahasiswa mampu merefleksi proses pembelajaran, serta mahasiswa menjadi lebih aktif (Yuliyanto et al., 2017). Dalam setiap pertemuan ditiap Materi-materi yang ada dalam Sejarah Asia Barat Kuno selalu dintegrasikan dengan lima tahapan PPR, yaitu: konteks, pengalaman, refleksi, aksi, dan evaluasi.

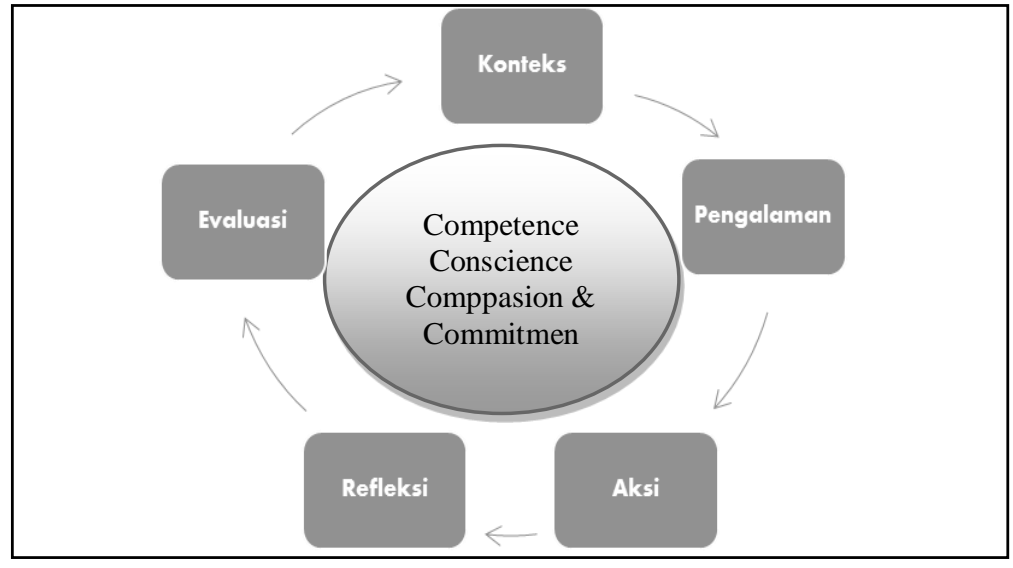

Gambar 1. Langkah-langkah pembelajaran PPR

\section{Konteks}

Apa yang perlu diketahui tentang mahasiswa (lingkungan, latar belakang, komunitas, dan potensi) untuk mengajar mereka dengan baik ? Kepedulian pribadi dan perhatian terhadap individu adalah ciri khas PPR, dan mensyaratkan bahwa tenaga pengajar (dosen) memahami konteks atau pengalaman hidup mahasiswa yang diajar khususnya dalam pembelajaran Sejarah Asia Barat Kuno. Dosen harus mengetahui sebanyak mungkin tentang konteks aktual di mana proses belajar mengajar terjadi (lingkungan Universitas Sanata Dharma). Seperti nilai-nilai dasar dari USD yakni, mencintai kebenaran, memperjuangkan keadilan, menghargai keberagaman, menjunjung tinggi keluhuran martabat manusia Jurnal Swadesi, Volume I Nomor 1 Tahun 2020 
(Universitas Sanata Dharma, 1955). Dosen juga perlu memahami dunia pelajar, termasuk cara-cara di mana keluarga, teman, teman sebaya, dan masyarakat yang lebih luas memengaruhi dunia itu dan memengaruhi pelajar menjadi lebih baik atau lebih buruk. Bahwa mahasiswa pendidikan sejarah USD bukan hanya datang dari DIY tetapi dari daerah lain yang memiliki kebudayaan dan juga kebiasaan yang berbeda satu sama lainnya.

\section{Pengalaman}

Dosen harus menciptakan kondisi di mana mahasiswa mengumpulkan dan mengingat kembali materi mereka sendiri pengalaman untuk menyaring apa yang sudah mereka pahami dalam kaitannya dengan fakta, perasaan, nilai, wawasan, dan intuisi yang mereka bawa ke pokok bahasan yang ada. Dosen kemudian membimbing peserta didik dalam mengasimilasi hal baru informasi dan pengalaman selanjutnya sehingga ilmunya tumbuh dalam kelengkapan dan kebenaran.

Dosen berperan menyediakan pengalaman bagi mahasiswa agar mahasiswa mengalami sendiri sehingga pengalaman itu menjadi miliknya. Wujud pengalaman dalam pembelajaran dapat berupa model pembelajaran yang digunakan. Model pembelajaran yang digunakan dipilih model yang dapat mengeksplorasi keaktifan mahasiswa. Aktif tidak hanya secara fisik namun juga secara mental, sehingga mahasiswa mengalami mengolah bahan pelajaran dan memetik maknanya bagi kehidupannya (Pratini, 2016)

\section{Refleksi: Mahasiswa menjadi lebih reflektif}

Dosen meletakkan dasar untuk mempelajari cara belajar dengan melibatkan mahasiswa dalam keterampilan dan teknik refleksi. Di sini ingatan, pemahaman, imajinasi, dan perasaan digunakan untuk menangkap makna esensial dan nilai dari apa yang sedang dipelajari pada mata kuliah Sejarah Asia Barat Kuno. Tujuannya untuk menemukan hubungannya dengan aspek lain dari pengetahuan mahasiswa dan aktivitas, dan untuk menghargai implikasinya dalam pencarian kebenaran yang berkelanjutan. Selain itu juga, refleksi bertujuan juga untuk memperbaiki proses pembelajaran (Yuliyanto et al., 2017).

\section{Tindakan: Mendorong mahasiswa untuk bergerak melampaui pengetahuan ke tindakan}

Dosen menyediakan kesempatan yang akan menantang imajinasi dan melatih kemauan mahasiswa untuk memilih tindakan yang terbaik dari apa yang telah mereka pelajari. Apa yang mereka lakukan sebagai hasil di bawah arahan dosen, meskipun mungkin tidak segera mengubah dunia menjadi komunitas global yang adil, damai, dan cinta. Akan tetapi setidaknya harus menjadi langkah pendidikan menuju tujuan tersebut bahkan jika itu hanya Jurnal Swadesi, Volume I Nomor 1 Tahun 2020 
mengarah pada pengalaman baru. Lebih jauh, refleksi dan tindakan konsekuen dalam bidang subjek yang dipertimbangkan.

\section{Evaluasi: Menilai Pertumbuhan Mahasiswa dalam Pikiran, Hati, dan Jiwa}

Kuis harian, UTS, tugas, praktikum dan UAS adalah instrumen yang familiar untuk menilai tingkat penguasaan pengetahuan dan keterampilan yang dicapai (lihat dokumen RPS mata kuliah Sejarah Asia Barat Kuno). Pedagogi Ignatian, bagaimanapun, bertujuan untuk evaluasi yang mencakup tetapi melampaui penguasaan akademis untuk pertumbuhan mahasiswa yang menyeluruh sebagai pribadi untuk orang lain. penilaian dalam PPR tidak hanya berupa soal yang bersifat kognittif, tetapi juga meliputi skala pengukuran untuk mengukur kepekaan hati nurani dan jiwa social mahasiswa. Penilaian tidak hanya meliputi aspek competence (kecerdasan pemikiran), tetapi meliputi aspek conscience (kepekaan hati nurani) serta aspek compassion (kepedulian sosial) (Fathoni, 2020).

Dosen yang jeli akan melihat indikasi apakah adanya pertumbuhan atau kurangnya keaktifan dalam diskusi kelas dan kemurahan hati mahasiswa dalam menanggapi kebutuhan bersama menjadi lebih sering. Dalam pelaksanaan pembelajaran Sejarah Asia Barat Kuno juga mengunakan media komik yang dibuat oleh mahasiswa pada mata kuliah Sejarah Asia Barat Kuno. Mediawati (2011) menyatakan bahwa menggunakan media pembelajaran komik dalam pembelajaran mata kuliah akutansi dapat m $\ldots$ tersebut dapat terjadi disebabkan oleh pembelaja tahapan dalam pelaksanaan pembelajarannya telah
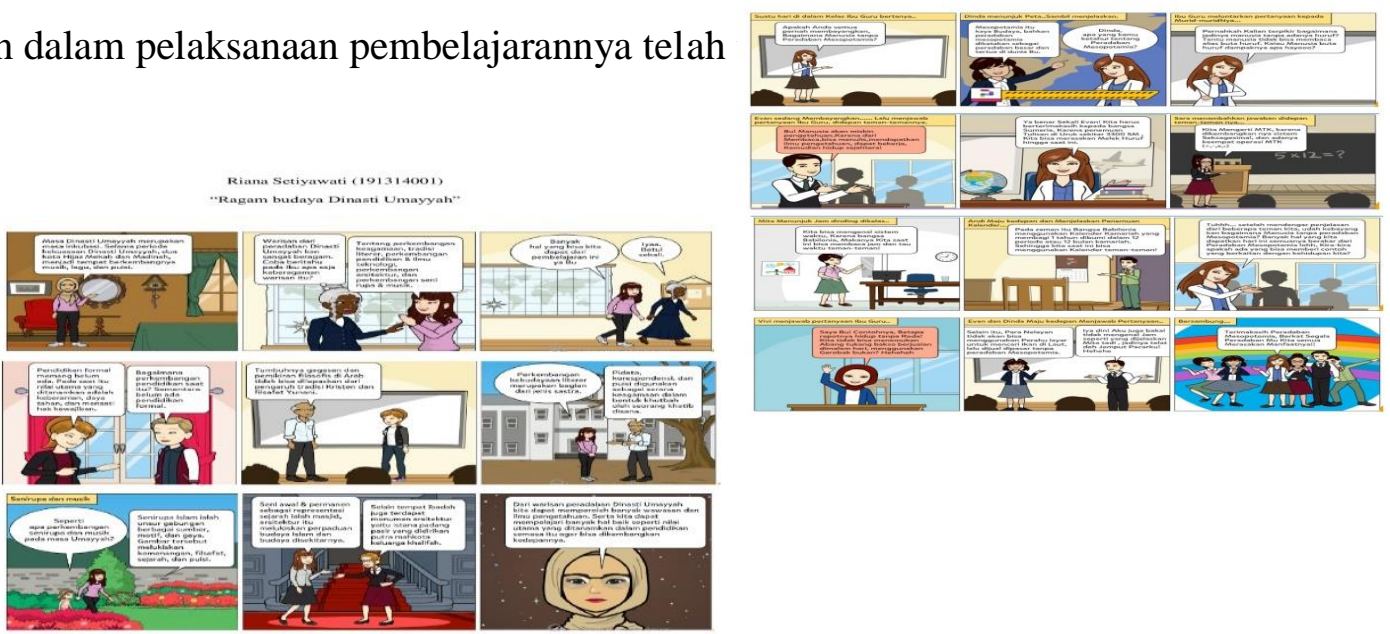

Gambar 2. Komik dalam Mata Kuliah Sejarah Asia Barat Kuno

Manfaat pembelajaran yang menerapkan pendekatan PPR ini dapat meningkatkan pemahaman mahasiswa dalam aspek sikap, dan nilai kemanusiaan. Refleksi yang dilakukan 
dalam setiap tahapan pembelajaran Sejarah Asia Barat Kuno akan membentuk hati nurani, nilai, sikap, dan seluruh cara berpikir mahasiswa sehingga akan melewati tahapan pemahaman, menjadi tahap tindakan (action) untuk mengambil keputusan yang bertanggung jawab dalam kehidupan sehari-hari. Diharapkan nilai-nilai yang diperoleh mahasiswa menjadi bermakna sehingga mereka dapat tumbuh menjadi pribadi yang mandiri, kompeten, utuh dan bertanggung jawab melalui materi pembelajaran Sejarah Asia Barat Kuno.

\section{Evaluasi dalam pembelajaran Sejarah Asia Barat Kuno berbasis PPR}

Stufflebeam menjelaskan bahwa Evaluasi ( evaluation ) adalah penilaian (assesment) yang dilakukan secara sistematis untuk menentukan nilai dan arti/makna (worth and merit) dari sesuatu yang sedang dievaluasi (Umasih, 2012). Umasih (2012)menjelaskan disadari bahwa praktik pendidikan selama ini masih mengandalkan pada pengukuran ke- mampuan otak kiri yaitu berpikir analitik, linier dan matematis. Sementara itu, otak kanan yang kompleks yaitu berpikir holistik, imaginatif dan kreatif belum mendapatkan porsi yang seimbang. Nilai atau watak kepribadian secara psikologis cenderung pada otak kanan. Oleh karena itu, kurikulum dan evaluasi pendidikan sarat mentelantarkan pendidikan nilai yang hanya mengukur berpikir analitik.

Oleh karena kritik tersebut, maka PPR dapat menjadi satu alternative untuk mengkur kemampuan mahasiswa secara komprehensif. Bahwa pembelajaran yang menerapkan pendekatan PPR mampu meningkatkan pemahaman mahasiswa bukan hanya dalam aspek sikap tetapi juga nilai kemanusiaan.

Ada tiga hal utama dalam pelaksanaan pembelajaran dengan menggunakan Paradigma Pedagogi Refeltif (PPR), yaitu pengalaman, refleksi, dan aksi. Dalam melaksanakan ketiga unsure tersebut fasilitator dibantu oleh unsur konteks sebelum pembelajaran dimulai dan evaluasi pembelajaran dilaksanakan (Suparno (2015) dalam artikel Hongkie Julie, Risalah Impelemnetasi Model-Model Pembelajaran Berbasis Pedagogi Ignasian, 2017). Evaluasi yang dilakukan yang terkait dengan kurikulum yang dikembangkan dalam kegiatan pembelajaran dalam konteks ini adalah pembelajaran Sejarah Asia Barat Kuno berbasis PPR. Maka evaluasi perlu dilakukan karena menjadi pembuktian berhasil tidaknya tujuan pendidikan sesuai dengan standar penilaian.

Standar penilaian yang dimaksud yakni, Standar Nasional Pendidikan Tinggi (SN Dikti). Dalam kaitan proses pembelajaran Sejarah Asia Barat Kuno berbasis PPR maka hal tersebut menjadi bagian dari Standar Pengelolaan Pembelajaran sesuai Permenristekdikti 44 Jurnal Swadesi, Volume I Nomor 1 Tahun 2020 
2015 tentang SN Dikti Pasal 38 (Kementerian Riset Teknologi dan PendidikanTinggi, 2019). Selain itu juga, secara khusus Standar penilaian juga harus merujuk pada misi program studi pendidikan sejarah USD yang telah dirumuskan. Dua dari empat misi berkaiatan dengan Paradigma Pedagogi Reflektif (PPR). Yakni, misi pertama, menyelenggarakan pendidikan holistik yang unggul dengan mengimplementasikan Paradigma Pedagogi Ignasian untuk menghasilkan calon pendidik sejarah yang berkarakter, cerdas, humanis, dan murah hati. Misi kedua, mengimplementasikan pendidikan calon guru sejarah dengan Paradigma Pedagogi Ignasian yang mengintegrasikan pengalaman, refleksi, tindakan, dan evaluasi dalam suasana dialogis (Prodi Pendidikan Sejarah USD, 2002).

\section{SIMPULAN}

Pembelajaran Sejarah Asia Barat Kuno merupakan pemahaman perkembangan sejarah kebudayaan dan peradaban masyarakat wilayah Asia Barat. Bahasannya mencakup sejarah pembentukan dan perkembangan kebudayaan Mesopothamia dan Persia, kebudayaan Arab pra Islam, perkembangan Islam masa Nabi Muhammad SAW, masa Khulafaur Rasyidin, masa dinasti Umayah dan Abbasiyah (Dinasti Syafawi dan Dinasti Turki Usmani awal). Sejarah Asia Barat Kuno juga menguraikan tentang dampak perkembangan budaya Arab bagi dunia dan perkembangan Islamisasi di Indonesia.

Pembelajaran Sejarah Asia Barat Kuno dilaksanakan pada mahasiswa Prodi Pendidikan Sejarah semester 2 dalam kurikulum 2016 dengan jumlah 2 Sistem Kredit Semester (SKS) dan 2 JP. Pandemi Covid-19 yang melanda Indonesia pada Mare 2020 juga mengubah pembelajaran perkuliahan yakni dari tatap muka menjadi menggunakan web belajar untuk melakukan PJJ. Para mahasiswa diberikan beberapa penugasan secara berkelompok sebelum masa pandemi covid-19.

Perkuliahan sejarah kawasan khususnya Sejarah Asia Barat Kuno akan terasa kering makna jika tidak dikemas dengan strategi pembelajaran yang inspiratif. Salah satu pemecahan masalahnya ialah peneliti sekaligus dosen pengampu menerapkan pendekatan atau Paradigma Pedagogi Reflektif (PPR) sebagai sarana pengajaran yang interaktif dan inspiratif.

Melalui perencanaan, pelaksanaan dan evaluasi yang benar dalam penerapan Paradigma Pedagogi Reflektif serta media komik yang menarik dalam perkuliahan Sejarah Asia Barat Kuno. Maka, mahasiswa mengalami peningkatan pada aspek competence yakni, penguasaan ilmu pengetahuan sesuai dengan bidangnya dalam hal ini pendidikan sejarah. conscience berarti mempunyai hati nurani yang dapat membedakan baik dan tidak baik. Serta Jurnal Swadesi, Volume I Nomor 1 Tahun 2020 
compassion yakni, Kepekaan untuk berbuat baik bagi orang lain yang membutuhkan, punya kepedulian pada orang lain. Bagi para civitas akademika dan pemerhati pendidikan sejarah, hasil penelitian ini diharapkan dapa mengintegrasikan pengajaran dengan penelitian secara maksimal sehingga manfaatnya dapat dirasakan bersama dan mampu dimaknai sebagai salah satu modal pembangunan bangsa.

\section{DAFTAR PUSTAKA}

Fathoni, B. (2020). REFLECTIVE PEDAGOGY AS HUMANISTIC LEARNING. 23(1), 79-91. https://doi.org/https://doi.org/10.20961/historika.v23i1.41239

Kementerian Riset Teknologi dan PendidikanTinggi. (2019). Standar Nasional Pendidikan Tinggi (SN Dikti). Universitas Sanata Dharma. https://usd.ac.id/lembaga/lpmai/wpcontent/uploads/2019/04/2.-Standar-Nasional-Pendidikan-Tinggi-SN-Dikti.pdf

Mediawati, E. (2011). PEMBELAJARAN AKUNTANSI KEUANGAN MELALUI MEDIA KOMIK UNTUK MENINGKATKAN PRESTASI MAHASISWA. Portal Jurnal Universitas Pendidikan Indonesia, 11(1). http://jurnal.upi.edu/penelitianpendidikan/view/1822/pembelajaran-akuntansi-keuangan--melalui-media-komik-untukmeningkatkan-prestasi-mahasiswa.html

Melissa, M. M. (2017). Paradigma Pedagogi Reflektif (PPR): Alternatif Pembelajaran Matematika untuk Mengembangkan Pengetahuan dan Karakter (Issue November). https://www.usd.ac.id/fakultas/pendidikan/s1pkim/f113/Paradigma Pedagogi Reflektif \%28PPR\%29-Margaretha.pdf

Pratini, H. S. (2016). IMPLEMENTASI PARADIGMA PEDAGOGI REFLEKTIF DALAM PEMBELAJARAN MATEMATIKA UNTUK MENINGKATKAN COMPETENCE, CONSCIENCE, DAN COMPASSION MAHASISWA. Elementary School, 3(1), 108113. https://doi.org/https://doi.org/10.31316/esjurnal.v3i1.372

Prodi Pendidikan Sejarah USD. (2002). Pendidikan Sejarah Fakultas Keguruan dan Ilmu Pendidikan. Universitas Sanata Dharma. https://www.usd.ac.id/fakultas/pendidikan/pen_sejarah/daftar.php?id=profile\&noid=45 \&offset $=0$

Qasim, M., \& Maskiah. (2016). Perencanaan Pengajaran dalam Kegiatan Pembelajaan. Jurnal Diskursus Islam, 04(3), 484-492. https://doi.org/https://doi.org/10.24252/jdi.v4i3.7365

Sulaiman, S. (2012). Pendekatan Konsep Dalam Pembelajaran Sejarah. Jurnal Sejarah Lontar, 9(1), 9-21. http://journal.unj.ac.id/unj/index.php/lontar/article/download/2373/1816/

Sutopo, H. . (2006). Metodologi Penelitian Kualitatif: Dasar Tori dan Terapannya dalam Penelitian Pendidikan Edisi Kedua. Universitas Sebelas Maret.

Umasih, U. (2012). Evaluasi Pembelajaran Sejarah Pada Sma Negeri Di Dki Jakarta. $\begin{array}{llll}\text { Paramita: } \quad \text { Historical Studies } & \text { Journal, }\end{array}$ https://doi.org/10.15294/paramita.v22i2.2122 
Universitas Sanata Dharma. (1955). Visi Misi Universitas Sanata Dharma. Www.Usd.Ac.Id. https://www.usd.ac.id/visimisi.php

Wijoyo, Y., Dwiprahasto, I., \& Rahayu, G. R. (2016). Pengembangan Strategi Pembelajaran berbasis Paradigma Pedagogi Reflektif untuk Meningkatkan Kompetensi Farmakoterapi dan Keterampilan KIE Mahasiswa Profesi Apoteker. Repository.Ugm.Ac.Id. http://etd.repository.ugm.ac.id/home/detail_pencarian/94666

Yuliyanto, E., Hidayah, F. F., Istyastono, E. P., Wijoyo, Y., \& Hartayu, T. S. (2017). Keunggulan Pembelajaran Reflective Pedagogy Paradigm ( Rpp ) Untuk Perbaikan Proses Pembelajaran. Seminar Nasional Pendidikan, Sains Dan Teknologi, 18-22. https://jurnal.unimus.ac.id/index.php/psn12012010/article/download/2971/2892 